\title{
Lip Gloss Containing Punica granatum Flower Extract and its Volumizing Effect
}

Sol-Hui Song, Hye-Jo Min, Min Kyung Kim, Jeong-hee Kim*

Division of Beauty Design, College of Natural Science, Wonkwang University, Iksan-si, Jeollabuk-do, Korea

\author{
*Corresponding author: Jeong-hee Kim, \\ Division of Beauty Design, College of \\ Natural Science, Wonkwang University, 460 \\ Iksan-daero, Iksan-si, Jeollabuk-do 54538, \\ Korea \\ Tel.: +82638506898 \\ Fax: +82638507301 \\ Email: jh@wku.ac.kr
}

Sol-Hui Song and Hye-Jo Min contributed equally to this work.

\section{Received April 09, 2020}

Revised June 02, 2020

Accepted June 05, 2020

Published June 30, 2020

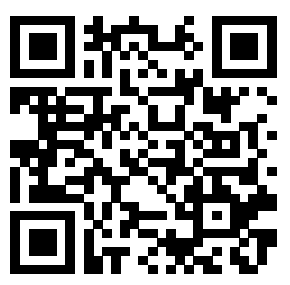

\begin{abstract}
Purpose: Lip plumpers are cosmetic agents for producing a temporary increase in lip volume. The topical action of lip plumpers has been rarely discussed in the dermatology literature. This study was conducted to assess the volumizing effect of lip cosmetic products. Methods: We prepared the three different lip glosses: the control (base lip gloss), sample A ( $2 \%$ Zingiber officinale root oil), and sample B (2\% Punica granatum flower extract). To assess their efficacy, 30 Korean female subjects (age range 30-49 years) with no negative clinical history of lip conditions were recruited. The impressions of lips were prepared at $0 \mathrm{~min}, 30 \mathrm{~min}$, and 3 weeks after applying the lip gloss. Scanning electron microscopy was used to scan the impressions. The volume changes in the impressions were assessed by 3D image analysis software. Results: For sample A, the intensity of wrinkles on the lip was decreased at 30 minutes after application, and the volumizing effect was seen at the same time. Both results were statistically significant. However, there was no statistically significant difference in wrinkle relief and volumizing effect 3 weeks later, as compared to the baseline. On the other hand, sample B both decreased wrinkle intensity and showed volumizing effects at $30 \mathrm{~min}$ that persisted 3 weeks later. Also, the wrinkle grade was measured by the experts. Conclusion: In conclusion, the sample containing the Punica granatum flower extract had long-term effects in relieving wrinkles and increasing the volume of the lips. These results support the possibility of developing functional cosmetics using Punica granatum flower extract.
\end{abstract}

Keywords: Punica granatum flower, Lip gloss, Wrinkle, Plumping effect, Volumizing effect

\section{Introduction}

최근 생활수준의 향상과 노령화 사회의 가속화로 인하여 외적인 미에 관심이 증가하면서(lee \& Ryu, 2017), 화장품 시장은 점차 세 분화 되어 가고 있다(Kwak, 2017). 얼굴의 주름뿐만 아니라 목 부 위나 손, 발 등 노화가 드러나는 신체 부위의 주름개선 기능성 화장 품이 출시되고 있다. 특히 색조 화장품 중에서는 입술 주름을 개선 하기 위한 플럼핑 효과의 제품이 소비자의 관심을 끌고 있다.

입술(vermilion)은 피부와 달리 표피의 과립층이 없어 멜라닌 세 포가 분포하지 않으며 모세혈관의 붉은 빛이 선명하게 보인다. 피부 는 약 16 개의 층으로 이루어져 있지만 입술은 3-5개의 층으로 이루 어져 다른 피부부위보다 각질층이 얇고(Jung \& Ryu, 2013) 외부 자 극이나 자외선에 민감하다(Bielfeldt et al., 2019). 특히 Kobayashi
(2004)의 연구에 따르면 입술과 피부의 생리적 특성 중 보습과 장벽 에 차이가 있으며, 입술이 피부보다 각질층 수분이 더 적으며 수분 손실도가 더 높음을 보고하였다. 따라서 입술의 보습 및 관리에 대 한 케어 제품 및 플럼핑 제품의 필요성을 인식할 수 있다.

립 제품류에 관련한 국내 외 특허출원 및 관련 연구를 살펴보면, 국내 립 플럼핑 제품의 개발 동향은 LG Household \& Health care Ltd. (2005)의 특허에서 다가알코올 및 액상오일로 이루어진 베이스 에 세라마이드 또는 그 유도체를 혼합하여 입술 주름 개선 립스틱을 제조하였다. 또한 AMOREPACIFIC Corporation (2008)의 특허에서 도 히알루론산 하이드로 겔 나노 입자를 이용한 제품이 보고되고 있 다. 이러한 연구의 한계점은 피부 주름 개선에 효능이 있는 기능성 원료를 입술에 적용한 사례로 볼륨감에 대한 관능평가를 제시하고 있다. 해외 선행연구로는 Mazzarello et al. (2017)의 연구에서 생강 


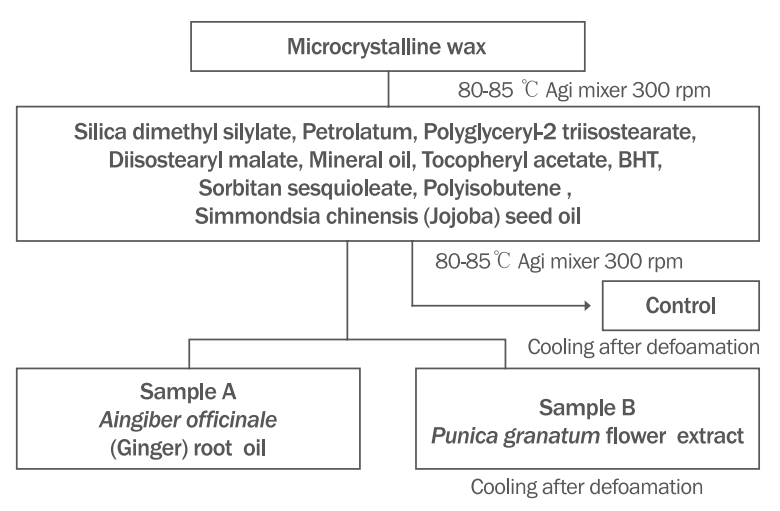

Figure 1. Diagram of lip-gloss manufacturing process.

에센셜 오일(Zingiber oil)을 이용한 립글로스 제품을 입술에 적용하 여 플럼핑에 대한 과학적인 효과를 보고하였으나 적용 시 온열감과 입술에 따끔거림의 통증을 느끼는 경우가 있다고 보고하였다.

따라서 온열감이나 자극감이 없으며 장기적인 입술주름 개선 및 플럼핑 효능이 예상되는 소재 발굴과 이를 활용한 화장품 제조, 과 학적인 플럼핑 효능평가가 수행될 필요성이 있다.

Punica granatum flower 추출물은 Hayouni (2011), Hassanpour Fard (2011), Nasiri (2017), Ahangarpour et al. (2012), Kaur et al. (2006) 등의 선행연구에서 항염증, 향균, 진균, 화상회복 등 다 양한 생물학적 효능이 있으며, 장기간 사용해도 전혀 부작용이 없는 것으로 보고하였다. 또한 Punica granatum flower 추출물의 폴리 페놀의 성분이 항산화제 역할을 하며 테르페노이드 성분이 항염증 성에 효과적으로 작용된다고 보고되었다.

이에 따라 본 연구에서는 온열감과 자극성이 없으며, 입술 주름

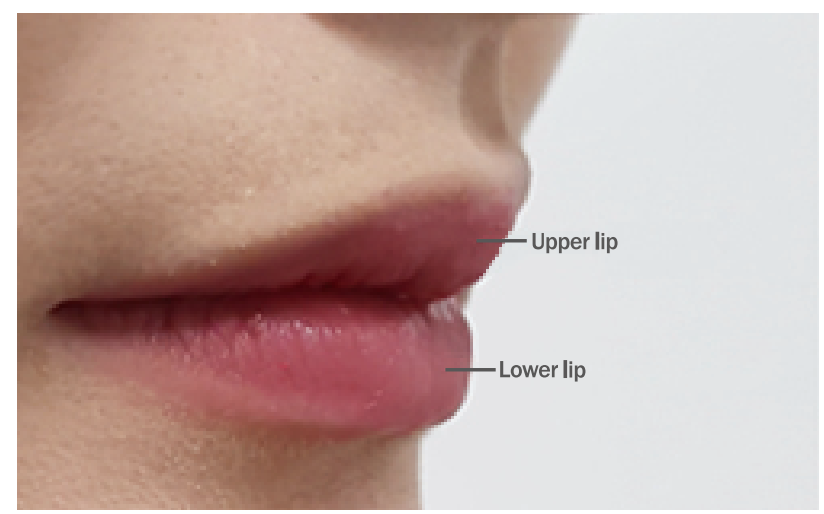

Figure 2. Soft-tissue landmarks used to measure anthropometric

완화의 효과가 예상되는 Punica granatum flower 추출물을 이용하 여 립글로스를 제조하고 사용 후 입술 볼륨감 및 주름 완화의 효과 를 평가하였다.

\section{Methods}

\section{1. 재료 및 제조}

Punica granatum flower 추출물은 서남아시아에서 자생한 석 류꽃을 이용한 Punica granatum fower extract (HALLSRAR, France)을 구입하여 사용하였다. 립글로스의 전체 조성은 $100 \mathrm{~g}$ 을 기준으로 control은 A, B상의 원료만 이용하여 제조하였다. Sample $\mathrm{A}$ 는 control 시료의 $\mathrm{A}$ 상과 $\mathrm{B}$ 상의 원료 조성에서 polyisobutene (Nippon Petrochemicals Co., Ltd., Japan)이 39.35 g으로 하고,

Table 1. Ingredients of lip-gloss

(Unit: g)

\begin{tabular}{|c|c|c|c|c|}
\hline & Ingredients & Control & Sample A & Sample B \\
\hline A & Microcrystalline wax & 3.50 & 3.50 & 3.50 \\
\hline \multirow{10}{*}{ B } & Silica dimethyl silylate & 1.00 & 1.00 & 1.00 \\
\hline & Petrolatum & 5.00 & 5.00 & 5.00 \\
\hline & Polyglyceryl-2 triisostearate & 8.50 & 8.50 & 8.50 \\
\hline & Diisostearyl malate & 8.50 & 8.50 & 8.50 \\
\hline & Mineral oil & 30.00 & 30.00 & 30.00 \\
\hline & Tocopheryl acetate & 0.10 & 0.10 & 0.10 \\
\hline & BHT & 0.05 & 0.05 & 0.05 \\
\hline & Sorbitan sesquioleate & 1.00 & 1.00 & 1.00 \\
\hline & Polyisobutene & 41.35 & 39.35 & 39.35 \\
\hline & Simmondsia chinensis (Jojoba) seed oil & 1.00 & 1.00 & 1.00 \\
\hline \multirow{2}{*}{ C } & Zingiber officinale (Ginger) root oil & & 2.00 & \\
\hline & Punica granatum flower extract & & & 2.00 \\
\hline \multicolumn{2}{|c|}{ Total } & 100.00 & 100.00 & \\
\hline
\end{tabular}


A

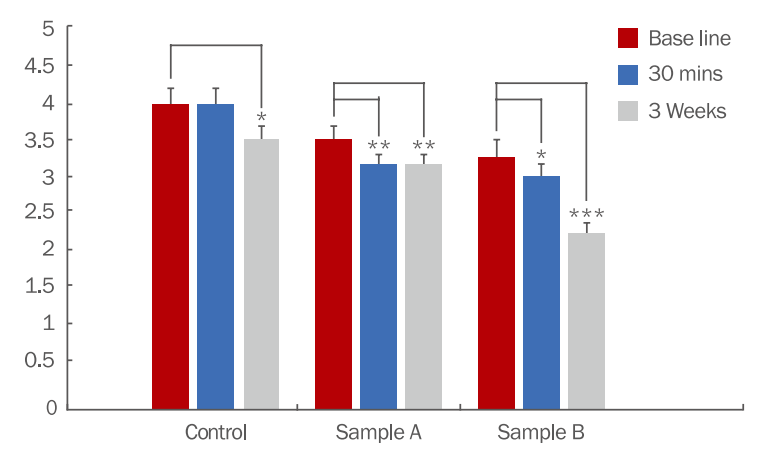

B

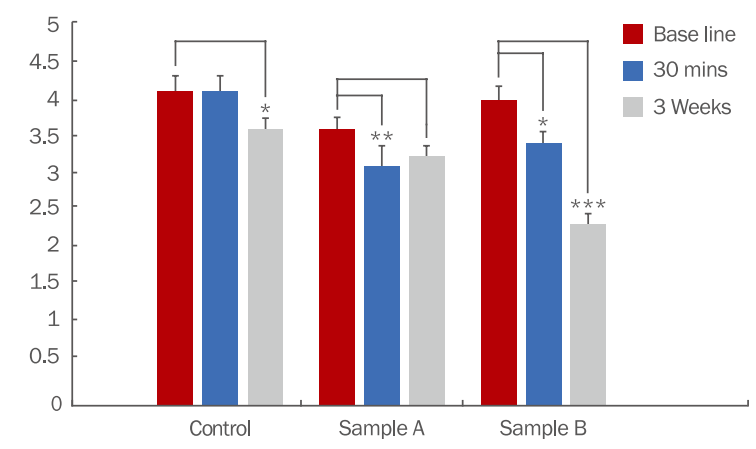

Figure 3. Expert evaluation of reduction in lip wrinkles.

(A) Upper lip; (B) lower lip. Data are show as means $p$-values were calculated by paired $t$-test. Statistical significance was found at ${ }^{*} p<0.05$, ${ }^{* *} p<0.01,{ }^{* * *} p<0.001$.

Mazzaello (2017)의 연구에서 보고된 플럼핑 효능 원료인 Zingiber officinale를 $2.00 \mathrm{~g}$ 추가하여 제조하였다. Sample B는 control 시 료와 동일한 base 기제 원료 조성에서 polyisobutene이 $39.35 \mathrm{~g}$ 으 로 하고, 플럼핑 효능 원료인 Punica granatum flower 추출물 2.00 $\mathrm{g}$ 을 첨가하여 립글로스를 제조하였다(Table 1 , Figure 1).

\section{2. 연구지원자 및 연구기간}

연구지원자의 구성은 30-49세에 해당하는 한국 여성 30명을 대 상으로 선정하였다. 선정 기준은 입술 관련 피부 질환이 없으며, 일 술 볼륨에 관련한 시술 및 반영구 문신을 하지 아니한 자로 하였다. 시료별 효능 평가를 위해 연구지원자를 control 10명, sample A 10 명, sample B 10 명으로 분류하였다. 제조된 립글로스의 인체적용시 험을 수행하기 위해 원광대학교 생명윤리위원회(Institution Review Board, IRB) 심사를 실시하고 연구수행의 승인을 허가받았다(연구 승인번호: WKIRB-201905-HR-032). IRB 승인 후 연구 지원자 를 대상으로 연구의 목적과 과정을 자세히 설명하였다. 특히 효능평 가 기간 내에는 다른 입술 화장품의 사용을 하지 않도록 하였으며, 1 일 3 회의 적용횟수 및 사용법을 적용 가이드에 따라 준수하도록 하 였다. 연구 기간은 2019년 8월 2일부터 2019년 10월 2일까지였다.

\section{3. 입술의 실리콘 레플리카}

입술의 주름 및 볼륨의 변화를 측정하기 위해 auto-mixing gun and polyvinyl siloxane (Delikit E\&E Light Body; Sherpa Korea, Korea)를 이용하여 입술의 실리콘 모형을 제작하였다. 레플리카는 인체의 형상을 그대로 복원체로 만들고 그 내면을 복사하여 체표의 변화를 관찰하는 방법으로 인체의 정립 시 및 동작 시의 체표 변화 까지도 구할 수 있는 장점이 있다(Kim et al., 1997). 제작 중 측정 오차를 최소화하기 위해서 동일한 실내 환경(실내온도 $20-25^{\circ} \mathrm{C}$, 습 도 40-60\% 정도 유지된 실내)에서 동일 측정자가 레플리카를 제작 하였다. 제작된 입술 모형의 기준점은 인중으로부터 내려오는 정중 앙을 중심으로 윗입술(upper lip), 아랫입술(lower lip)을 동시에 측 정하였다(Figure 2).

\section{4. 입술 모형의 SEM 측정}

Analytical High Resolution Scanning Electron Microscope (HR-SEM, SU-70; Hitachi, Japan)을 이용하여 촬영하였다. $\mathrm{HR}-\mathrm{SEM}$ 은 전자빔을 시료에 주사하여 시료로부터 발생한 이차전 자를 검출하여 고분해능의 이미지 및 성분분석이 가능한 장비이다. 시료의 표면, 단면, 나노스케일의 입자크기 분석 등을 고분해능(1.0 $\mathrm{nm} @ 15 \mathrm{kV}$ )의 SE 이미지 분석을 수행한다. $\mathrm{EDS}$ 를 이용한 정성, 정량분석의 화학분석과 $\mathrm{EBSD}$ 를 이용한 시료의 texture와 같은 구 조분석이 가능하다. 이와 같은 이미지분석, 화학분석, 구조분석이

Table 2. The descriptive scale used in the assessment of cutaneous wrinkling

\begin{tabular}{|c|c|c|c|}
\hline Score & Coarse wrinkle & Fine wrinkle ${ }^{\dagger}$ & Linear wrinkle $^{\ddagger}$ \\
\hline 1 & & & $1-2$ \\
\hline 2 & & $1-2$ & \\
\hline 3 & & $>3$ & \\
\hline 4 & $1-2$ & $3-5$ & \\
\hline 5 & $>3$ & & \\
\hline
\end{tabular}

${ }^{*}$ Coarse wrinkle, deep line, furrow; ${ }^{\dagger}$ Fine wrinkle, shallow line; ${ }^{\ddagger}$ Linear wrinkle, superficial shallow line. 
시료의 같은 지점에서 동시에 분석 가능하다. $\mathrm{SEM}$ 촬영을 위해 $\mathrm{Pt}$ or Au ion coater (E-1030; Hitachi, Japan)을 이용하여 분석시료 를 코팅한 후 이미지를 촬영하였다.

\section{SEM 측정 영상의 전문가 집단 육안평가}

$\mathrm{SEM}$ 측정 영상에 대한 육안평가를 위해 전문가 집단을 선정하였
다. 전문가 집단은 피부과 전문의 또는 피부미용 전공교육 경력 5 년 이상인 전문가 총 30 명으로 구성하였다. 입술 주름에 대한 평가 기 준은 $\operatorname{Suh}$ (2007)의 연구를 참고하였다. 입술 주름은 등급에 따라 은 굵은 주름(coarse wrinkle), 잔주름(fine wrinkle), 얇은 주름(linear wrinkle)으로 각각 정의하고, 주름의 개수에 따라 해당 점수(score) 를 표시하였다(Table 2).

Table 3. Verification of homogeneity on the subject's lip

\begin{tabular}{llcccccc}
\hline Variable & & Control $(\mathrm{N}=10)$ & Sample $\mathrm{A}(\mathrm{N}=10)$ & Sample B $(\mathrm{N}=10)$ & $F$ & $p$ \\
Wrinkle & Upper lip & $6.75 \pm 1.68$ & $6.57 \pm 1.76$ & $6.01 \pm 1.68$ & 0.478 & 0.625 \\
& Lower lip & $5.29 \pm 0.74$ & $5.37 \pm 1.05$ & $5.99 \pm 0.51$ & 2.079 & 0.145 \\
Volume & Upper lip & $5.63 \pm 2.41$ & $6.88 \pm 2.47$ & $7.18 \pm 2.77$ & 1.004 & 0.380 \\
& Lower lip & $6.94 \pm 1.82$ & $7.31 \pm 3.08$ & $8.22 \pm 2.60$ & 0.616 & 0.548 \\
\hline
\end{tabular}

Data are expressed as means \pm standard deviation. Data analysis are use through Levene's test.

Table 4. Scanning electron microscopy of representative impressions of each sample on the lip surface

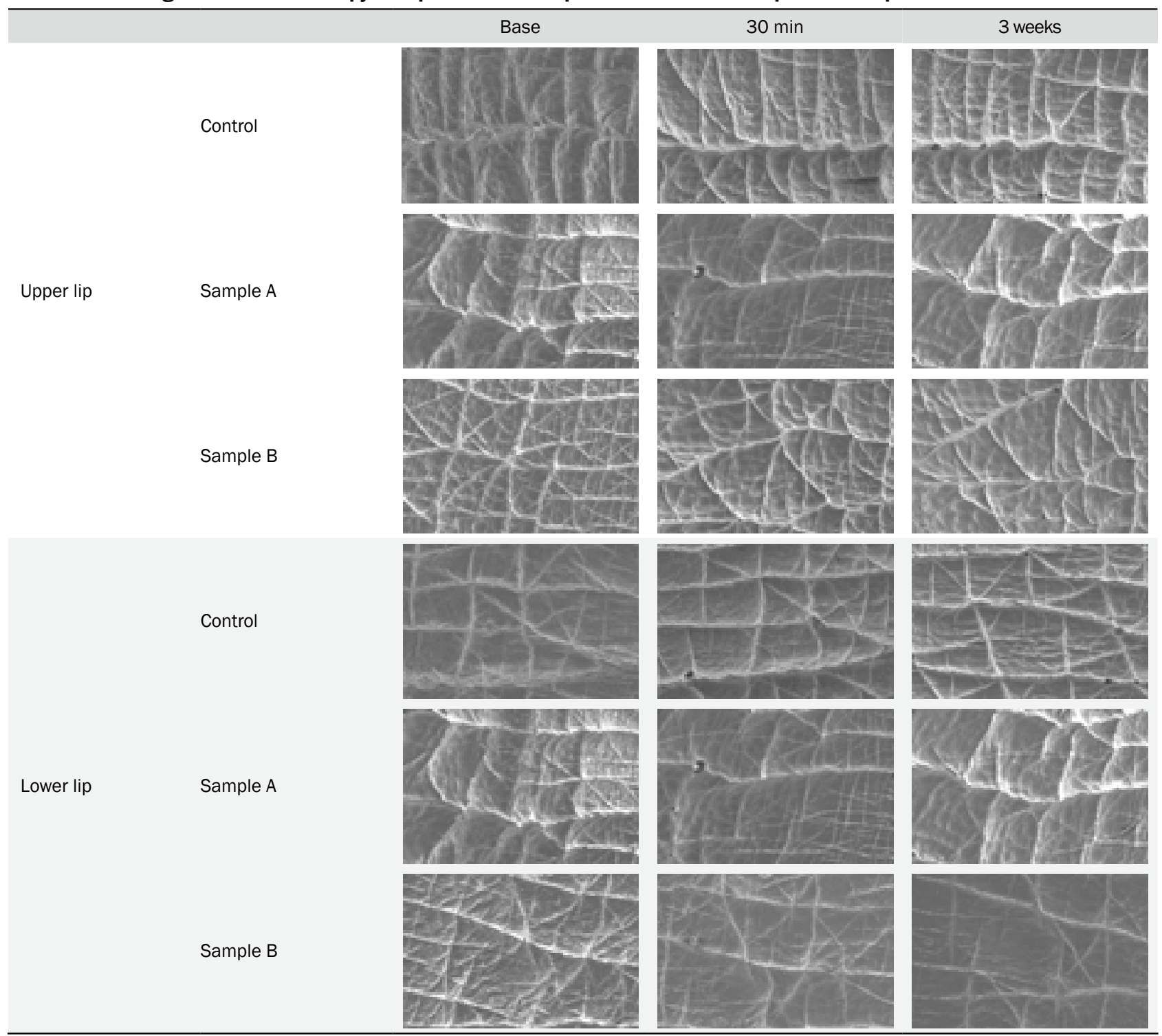




\section{3D analysis software를 이용한 입술 주름 및 볼륨 측정}

$\mathrm{SEM}$ 으로 촬영된 이미지는 $3 \mathrm{D}$ analysis software $\mathrm{MEX}^{\circledR} 6.1$ (Alicona, Austria)을 이용해 3D로 변환하여 입술 주름과 볼륨감을 분석하였다. 입술의 측정 부위는 인중으로부터 내려오는 입술의 정 중앙선상의 윗입술과 아랫입술을 측정하여 각 이미지의 면적에 대 한 주름의 평균값을 구하였다. 입술볼륨에 대한 3 차원 측정은 입술 중앙의 측면부위 이미지에서 표면 굴곡의 평균값으로 휘어지는 가 상의 원을 중심으로 하였다. 이 가상의 원 중심을 곡률중심으로 정 의하고 곡률의 반지름 값을 구하였다

\section{7. 자료 분석}

자료 분석은 SPSS program을 이용하여 실험 결과의 평균과 표 준편차, 변화값 등의 기술통계를 실시하였다. 관능평가의 비교분석 은 ANOVA를 실시하고, 각 집단 간 차이를 검증하기 위해 Duncan 의 사후 검증을 이용하였다.

\section{Results and Discussion}

실험 전 control, sample A, sample B 집단 내에 지원자들(각 집
단내 표본수=10)의 입술 주름과 볼륨 상태에 대한 동질성 여부를 등 분산가정검정(Levene's test)을 사용하여 검증하였다(Table 3). 주름 (wrinkle), 볼륨(volume) 측정 결과, 세 집단 간 피험자의 입술 주름 및 볼륨 측정값들이 통계적으로 유의한 차이가 없어 집단별 입술 주 름과 볼륨 상태의 동질성을 확인하였다.

연구지원자의 입술 모형을 $\mathrm{SEM}$ 으로 측정한 각 그룹별 대표 영 상은 Table 4 와 같다. 전문가 30 명이 각 그룹별 SEM 영상을 육안 으로 평가한 결과는 Table 5 와 같다. 주름의 변화에 대한 평가 결과 를 $t$-test로 비교한 결과, control 그룹은 base line과 $30 \mathrm{~min}$ 후에 는 주름 변화의 차이가 없었으나, 3 주 후 변화가 나타났다 $(p<0.05)$. Sample A는 baseline보다 $30 \mathrm{~min}$ 후 윗입술과 아랫입술 모두 주 름 깊이에 대한 평가 등급이 낮아지면서 통계적으로 유의한 차이가 나타났다 $(p<0.01)$. 그러나 3 주 후에는 윗입술의 경우 주름깊이에 대한 평가가 낮아졌지만 $(p<0.05)$ 아랫입술의 경우 차이가 없었다. Sample B는 $30 \mathrm{~min}$ 후 입술의 주름이 개선되었으며 $(p<0.05), 3$ 주 후에도 지속적으로 주름의 등급이 개선된 것 $(p<0.001)$ 으로 평가되 었다(Figure 3).

주름 깊이의 변화를 $3 \mathrm{D}$ analysis software을 이용하여 분석한 결 과는 Table 6 와 같다. 각 시료를 사용 한 후 주름 깊이가 변화하였는 지에 대한 차이를 $t$-test로 비교한 결과, 윗입술의 경우 control 그

Table 5. The grade of lip wrinkles after using lip gloss samples

\begin{tabular}{|c|c|c|c|c|c|c|}
\hline \multirow{2}{*}{ Variable } & \multicolumn{2}{|c|}{ Base line } & \multicolumn{2}{|c|}{$30 \mathrm{~min}$} & \multicolumn{2}{|c|}{3 weeks } \\
\hline & Upper lip & Lower lip & Upper lip & Lower lip & Upper lip & Lower lip \\
\hline Control & $4.00 \pm 0.47$ & $4.10 \pm 0.56$ & $4.00 \pm 0.47$ & $4.10 \pm 0.56$ & $3.60 \pm 0.51$ & $3.80 \pm 0.78$ \\
\hline Sample A & $3.60 \pm 0.69$ & $3.60 \pm 0.69$ & $3.10 \pm 0.87$ & $3.10 \pm 0.87$ & $3.10 \pm 0.99$ & $3.30 \pm 0.94$ \\
\hline Sample B & $3.33 \pm 0.70$ & $4.00 \pm 0.00$ & $2.89 \pm 0.78$ & $3.33 \pm 0.70$ & $2.11 \pm 0.60$ & $2.11 \pm 0.92$ \\
\hline
\end{tabular}

Data shows means \pm standard deviation; Control, base lip gloss; Sample A, base lip gloss containing Zingiber officinale root oil 2\%; Sample B, base lip gloss containing Punica granatum flower extract $2 \%$.

Table 6. The changes of wrinkle depth after using lip gloss sample

(Unit: $\mu \mathrm{m})$

\begin{tabular}{|c|c|c|c|c|c|c|c|}
\hline & & \multicolumn{2}{|c|}{ Base line } & \multicolumn{2}{|c|}{$30 \mathrm{~min}$} & \multicolumn{2}{|c|}{3 weeks } \\
\hline & & Upper lip & Lower lip & Upper lip & Lower lip & Upper lip & Lower lip \\
\hline \multirow{3}{*}{ Wrinkle } & Control & $6.75 \pm 1.68$ & $5.29 \pm 0.74$ & $6.34 \pm 1.35$ & $4.77 \pm 0.80$ & $6.28 \pm 1.59$ & $4.57 \pm 0.90$ \\
\hline & Sample A & $6.57 \pm 1.76$ & $5.37 \pm 1.05$ & $5.72 \pm 1.73$ & $4.46 \pm 1.38$ & $5.87 \pm 1.57$ & $4.77 \pm 1.04$ \\
\hline & Sample B & $6.01 \pm 1.68$ & $5.99 \pm 0.51$ & $5.62 \pm 1.75$ & $5.00 \pm 0.54$ & $5.34 \pm 1.50$ & $4.26 \pm 1.05$ \\
\hline
\end{tabular}

Data shows means \pm standard deviation. Control, base lip gloss; Sample A, base lip gloss containing Zingiber officinale root oil $2 \%$; Sample B, base lip gloss containing Punica granatum flower extract $2 \%$.

Table 7. The changes of the radius curvature in lip protrusion after lip gloss applications

(Unit: $\mathbf{m m})$

\begin{tabular}{|c|c|c|c|c|c|c|c|}
\hline & & \multicolumn{2}{|c|}{ Base line } & \multicolumn{2}{|c|}{$30 \mathrm{~min}$} & \multicolumn{2}{|c|}{3 weeks } \\
\hline & & Upper lip & Lower lip & Upper lip & Lower lip & Upper lip & Lower lip \\
\hline \multirow{3}{*}{ Wrinkle } & Control & $5.63 \pm 2.41$ & $6.94 \pm 1.82$ & $7.01 \pm 3.68$ & $8.38 \pm 2.09$ & $6.81 \pm 2.84$ & $9.21 \pm 1.96$ \\
\hline & Sample A & $6.88 \pm 2.47$ & $7.31 \pm 3.08$ & $7.95 \pm 2.11$ & $10.78 \pm 3.93$ & $7.33 \pm 2.22$ & $9.24 \pm 4.88$ \\
\hline & Sample B & $7.58 \pm 2.90$ & $8.58 \pm 2.70$ & $9.35 \pm 3.86$ & $10.46 \pm 3.35$ & $12.02 \pm 3.94$ & $12.22 \pm 4.26$ \\
\hline
\end{tabular}

Data shows means \pm standard deviation. Control, base lip gloss; Sample A, base lip gloss containing Zingiber officinale root oil $2 \%$; Sample B, base lip gloss containing Punica granatum flower extract $2 \%$. 
A

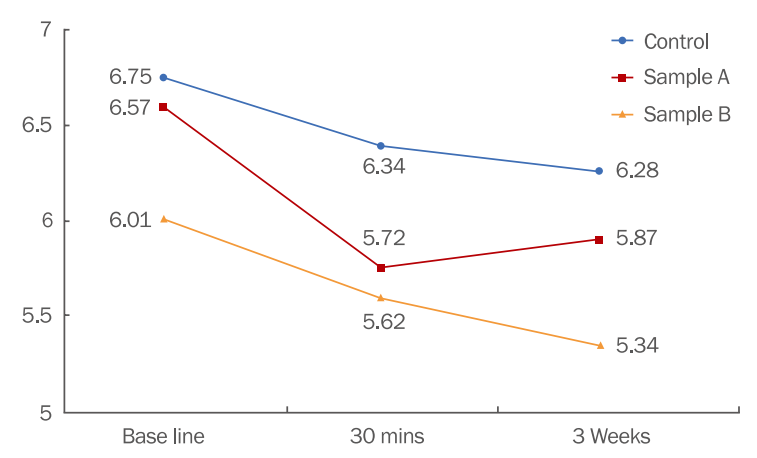

B

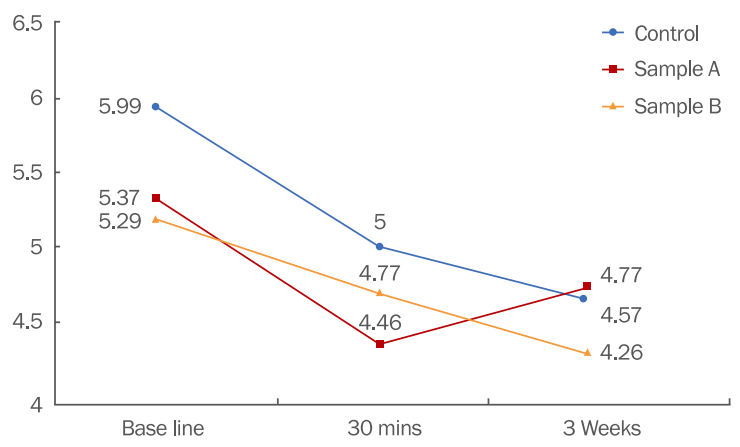

Figure 4. Differences in lip wrinkle depth after using lip gloss.

(A) Upper lip; (B) lower lip. Data are show as means $p$-values were calculated by paired $t$-test. Statistical significance was found at ${ }^{*} p<0.05$, ${ }^{* *} p<0.01,{ }^{* * *} p<0.001$.

룹, sample A, sample B의 모든 그룹이 base line과 $30 \mathrm{~min}$ 후의 변화에서 주름 깊이의 차이가 없었으며 3 주 후와 비교한 결과에서도 주름 깊이의 차이가 나타나지 않았다. 아랫입술의 경우 control 그룹 은 base line과 $30 \mathrm{~min}$ 후에는 주름 깊이의 차이가 없었으나, base line과 3 주 후 변화를 비교한 결과 3 주 후에 주름 깊이가 감소되었음 을 알 수 있었다 $(p<0.05)$. Sample A는 base line보다 $30 \mathrm{~min}$ 후 주 름의 깊이의 수치가 감소하여 통계적으로 유의한 차이가 나타났다 $(p<0.001)$. 그러나 3 주 후에는 base line과 비교했을 때 유의한 차 이가 없었다. Sample B는 $30 \mathrm{~min}$ 후 입술의 주름이 개선되었으며 ( $p<0.01), 3$ 주 후에도 지속적으로 주름의 깊이가 개선된 것으로 나 타났다 $(p<0.001$, Figure 4). 주름 깊이의 측정 결과에서 측정단위가 $\mu \mathrm{m}$ 이기 때문에 통계적인 유의차가 나타났다고 하더라도 실제적인 분석를 감안하였을 때, 결과만으로는 주름 깊이 완화에 효능이 있다 고 단정하기는 어려울 것으로 사료된다. 따라서 이러한 분석결과에 대한 실제적인 보완을 위해 전문가 집단이 입술 주름에 대한 SEM 영상을 평가한 결과를 제시하였다. 전문가 집단의 $\mathrm{SEM}$ 영상에 대한 육안평가 결과에서도 주름 깊이의 측정 결과 분석과 유사한 결과를 보였는데 sample B를 입술에 적용한 후 아랫입술의 경우 $30 \mathrm{~min}$ 과 3 주 후 경과 모두 주름 깊이가 완화되었음을 확인하였다.

입술 볼륨의 변화를 분석한 결과는 Table 7과 같다. 각 시료 적용 후 입술 볼륨 변화를 $t$-test로 비교한 결과, control의 경우 윗입술 에서는 볼륨의 변화 비교에서 유의한 차이가 나타나지 않았으나 아 랫입술의 경우에는 사용 3 주 후 base line과 비교하였을 때 볼륨이 약간 증가하였다 $(p<0.05)$. Sample A 적용 후, 윗입술의 볼륨 변화 를 비교 결과에서는 유의한 차이가 나타나지 않았다. 아랫입술의 경 우 base line과 비교하였을 때 사용 후 $30 \mathrm{~min}$ 에 볼륨감이 크게 증 가하여 유의한 차이가 있었다 $(p<0.01)$. 그러나 3 주 후에는 base line 과 비교하였을 때 유의한 차이를 보이지 않았다. 이는 Mazzarello et al. (2017)의 Zingiber officinale root oil을 함유한 립 플럼퍼를
이용한 플럼핑 효과 연구에서 립 플럼퍼 사용 $15 \mathrm{~min}, 30 \mathrm{~min}$ 에 일 시적으로 플럼핑 효과가 증가했지만, $30 \mathrm{~min}$ 이후부터 점차 효과 가 감소한 것과 동일한 결과로 Zingiber officinale root oil를 함유 한 sample A는 $30 \mathrm{~min}$ 후부터 일시적인 효과는 나타났다. 반면, Punica granatum flower 추출물을 함유한 sample $\mathrm{B}$ 는 윗입술의 경우 사용 3 주 후에는 볼륨감이 증가하였으며 $(p<0.01)$, 아랫입술 의 경우 base line과 사용 후 $30 \mathrm{~min}$ 후에 볼륨의 차이가 나타났으며 $(p<0.001), 3$ 주 후 볼륨 변화를 측정한 결과에서도 볼륨이 증가하여 $(p<0.01)$ 일시적인 효과와 지속적인 효과가 함께 나타나는 것을 알 수 있었다(Figure 5).

\section{Conclusion}

이 연구에서는 플럼핑 효능이 예상되는 Punica granatum flower 추출물을 이용하여 립글로스를 제조하였고, 인체적용실험을 수행하 여 입술의 주름의 완화와 볼륨감 향상의 효능 평가를 실시하였다.

각 시료별 주름 깊이 완화에 대한 효능평가를 위해 SEM 영상 자 료를 $3 \mathrm{D}$ analysis software을 이용하여 측정치를 비교 분석한 결 과 Sample A는 $30 \mathrm{~min}$ 후 주름의 깊이의 수치가 감소하였으나 3 주 후에는 base line과 비교했을 때 유의한 차이가 없었다. Sample $\mathrm{B}$ 는 $30 \mathrm{~min}$ 후 입술의 주름이 개선되었으며, 3 주 후에도 지속적으 로 주름의 깊이가 개선되어진 것으로 나타났다. 그러나 $3 \mathrm{D}$ analysis software을 이용하여 측정한 입술 주름의 측정 단위가 매우 미세하 기 때문에 실제적인 주름 완화 효과를 단언하기가 어렵다고 판단하 였다. 따라서 이에 대한 보완으로 전문가 집단을 중심으로 한 $\mathrm{SEM}$ 영상 자료의 육안 평가를 실시하였다. 그 결과 sample $\mathrm{A}$ 는 $30 \mathrm{~min}$ 후에서 주름 평가 지수가 낮게 평가되어 유의한 차이가 나타났다. Sample B의 경우 $30 \mathrm{~min}$ 후 주름 평가 지수가 낮게 평가되었으며, 
A

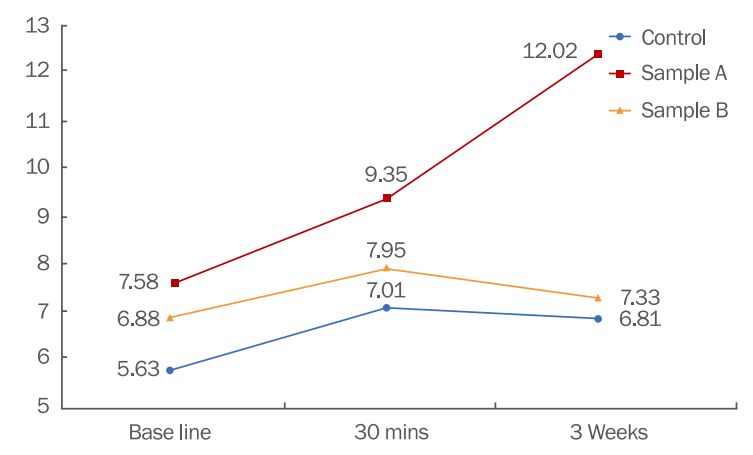

B

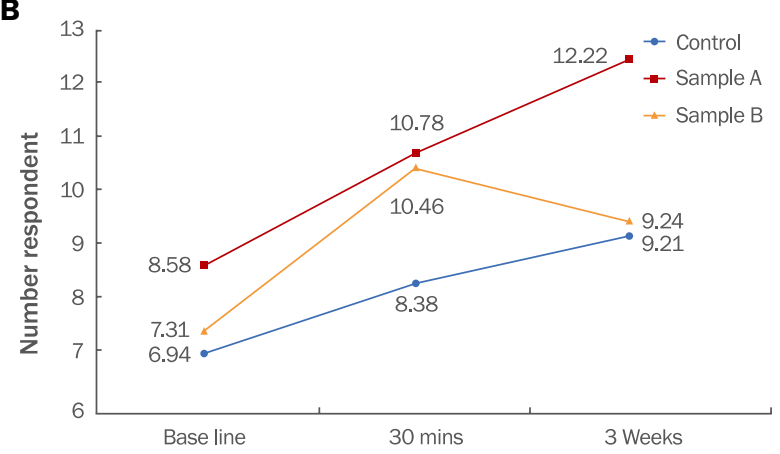

Figure 5. Differences in the radius of lip curvature $(\mathrm{mm})$ after using the lip gloss by $3 \mathrm{D}$ analysis system MEX®.

(A) Upper lip; (B) lower lip. Data are show as means $p$-values were calculated by paired $t$-test. Statistical significance was found at ${ }^{*} p<0.05$; ${ }^{* *} p<0.01 ;{ }^{* * *} p<0.001$.

특히 3주 후에는 base line의 평균 주름 등급이 fine wrinkle이었는 데 3주 후 Linear wrinkle 등급으로 변화하여 주름이 완화된 것으로 평가되었다. 이에 따라 주름 깊이 변화에 대하여 sample A의 경우 $30 \mathrm{~min}$ 경과 후 효능이 있었지만 3 주 후 지속적인 효능이 나타나지 않았으며 sample B의 경우 $30 \mathrm{~min}$ 후와 3 주 후 주름 깊이가 감소하 는 지속적인 변화를 확인하였다.

플럼핑 효능을 평가한 결과, sample A는 즉각적 사용에서 볼륨이 증가하는 효과를 확인하였으며 이러한 결과는 선행연구결과와 일치 하였다. Sample B는 사용 $30 \mathrm{~min}$ 후와 3 주 후 모두 플럼핑 효과가 유지되는 것으로 나타났다.

결론적으로 Zingiber officinale root oil의 경우 일시적인 사용 에서 주름감소 및 플럼핑 효능이 나타났으나 Punica granatum flower 추출문의 경우 일시적인 사용과 3 주 동안의 지속적인 사용시 주름감소 및 플럼핑 효능이 유지되는 것을 알 수 있었다.

현재 플럼핑 효과, 주름 완화의 립 화장료가 개발 및 출시되고 있 지만 실제 사용 시 플럼핑 효과의 지속성이나 플럼핑 효과에 대한 과학적 데이터의 제시가 미비한 실정이다. 이 연구에서는 Punica granatum flower 추출물을 이용한 립글로스를 제조하고 이에 대 한 주름감소 및 플럼핑 효과를 제시하였다. 추후 연구에서는 Punica granatum flower 추출물이 함유된 립글로스 적용 후 입술의 생리적 변화인 TEWL, 수분함유량, 유분, 주름량에 대한 분석을 통해 기능 성 화장품 개발 가능성을 제시하고자 한다.

This work is part of the Sol-Hui Song's Ph.D. thesis at the Wonkwang University, Iksan, Korea.

\section{Acknowledgements}

본 연구는2019년 대한민국 교육부와 한국연구재단의 지원을 받아 수행된 연구임(NRF-2019S1A5B5A07088081).

\section{Author's contribution}

SHS and HJM contributed equally to this work. SHS and HJM designed all experimental investigations. MKK performed experiments and wrote manuscript. JHK oversaw the project.

\section{Author details}

Sol-Hui Song (Visiting Professor) Department of Beauty Design, Wonkwang University 460, Iksan-daero, Iksan-si, Jeollabuk-do 54538, Korea; Hye-Jo Min (Visiting Professor) Department of Beauty Design, Wonkwang University 460, Iksan-daero, Iksan-si, Jeollabuk-do 54538, Korea; Min Kyung Kim (Graduate student), Department of Beauty Design, Wonkwang University 460, Iksan-daero, Iksansi, Jeollabuk-do 54538, Korea; Jeong-hee Kim (Professor), Department of Beauty Design, Wonkwang University 460, Iksan-daero, Iksan-si, Jeollabuk-do 54538, Korea.

\section{References}

Ahangarpour A, Heidari R, Abdolahzadeh M, Oroojan AA. Antispasmodic effects of aqueous and hydroalcoholic Punica granatum flower extracts on the uterus of nonpregnant rats. Journal of Reproduction \& Infertility, 13: 138-142, 2012.

AMOREPACIFIC Corporation. Cosmetic composition for lipplumping and wrinkle-improvement of lips. Korea patent No. 1014210490000, 2008.02.29.

Bielfeldt S, Blaak J. Laing S, Schleißinger M, Theiss C, 
Wilhelm KP, Staib P. Deposition of plant lipids after single application of a lip care product determined by confocal raman spectroscopy, corneometry and transepidermal water-loss. International Journal of Cosmetics Science, 41: 281-291, 2019.

Hassanpour Fard M, Ghule AE, Bodhankar SL, Dikshit M. Cardioprotective effect of whole fruit extract of pomegranate on doxorubicin-induced toxicity in rat. Pharmaceutical Biology, 49: 377-82, 2011.

Hayouni EA, Miled K, Boubaker S, Bellasfar Z, Abedrabba M, Iwaski H, Oku H, Matsui T, Limam F, Hamdi M. Hydroalcoholic extract based-ointment from Punica granatum L. peels with enhanced in vivo healing potential on dermal wounds. Phytomedicine, 18: 976984, 2011.

Jung JH, Ryu HW. Validity of Japanese rice cake in the assessment of moisturizing capacity for lip make-up products. Asian Journal of Beauty and Cosmetology, 11: 577-584, 2013.

Kaur G, Jabbar Z, Athar M, Alam MS. Punica granatum (pomegranate) flower extract possesses potent antioxidant activity and abrogates Fe-NTA induced hepatotoxicity in mice. Food and Chemical Toxicology, 44: 984-993, 2006.

Kim HK, Kweon SH, Kim SJ, Park EJ, Seo CY, Lee SN, Jeon EK, Jo JM. Clothing ergonomics experimental methodology. Kyomumsa, Seoul, P46, 1997.

Kobayashi $\mathrm{H}$, Tagami $\mathrm{H}$. Functional properties of the surface of the vermilion border of the lips are distinct from those of the facial skin. British Journal of Dermatology, 150: 563-567.

Kwak MS. Analysis of research trends in development of functional cosmetic materials for wrinkle improvement. Journal of Beauty Art Management, 11: 1-19, 2017.

Lee JM, Ryu MJ. Efficacy of cosmetic materials using Aronia melanocarpa leaf extracts. Asian Journal of Beauty and Cosmetology, 16: 179-190, 2018.

LG Household \& Health care Ltd. A lipstick having core and shell structure containing water soluble anti-wrinkle compound and manufacturing method thereof. Korea patent No.1005823480000, 2005.01.08.

Mazzarello V, Solinas G, Bandiera P, Pomponi V, Piu G, Ferrari $M$, Montella A. How long does the volumizing effect of a Zingiber officinale-based lip plumper last. International Journal of Cosmetic Science, 39: 373-378, 2017.

Nasiri E, Hosseinimehr SJ, Akbari J, Azadbakht M, Azizi $\mathrm{S}$. The effects of Punica granatum flower extract on skin injuries induced by burn in rats. Advances in Pharmacological Sciences, 2017: 1-8, 2017.

Suh KS, Lee JW, Choi SY, Kim ST. The effect of asiaticoside on the improvement of lip. Kosin Medical Journal, 22: 220-231, 2007. 


\section{국문초록}

\section{Punica granatum Flower 추출물을 함유한 립글로스 제조 및 플럼핑 효과}

송솔희, 민혜조, 김민경, 김정희

원광대학교 자연과학대학 뷰티디자인학부, 전라북도 익산시, 한국

목적: 입술 플럼핑은 입술의 볼륨감을 일시적으로 증가시키기 위한 화장품이다. 입술 플럼핑의 국소작용 효과는 피부학 문헌에서 거의 논의되지 않았다. 본 연구는 립 화장품의 볼륨감 효과에 대한 평가를 위해 실시되었다. 방법: 컨트롤(베이스 립글로스), 샘플 $\mathrm{A}$ (2\% 생강 오일), 샘플 B ( $2 \%$ 석류꽃 추출물) 3 가지 립글로스를 준비했다. 그 효능을 평가하기 위해 입술에 피부질환이 없는 30 명의 한국인 여성 피험자(30-49세)를 모집했다. 입술의 모형은 $0 \mathrm{~min}, 30 \mathrm{~min}, 3$ 주의 시간에 립글로스를 바른 후 제작되었다. SEM은 모형을 스캔하는 데 사용되었다. 모형의 볼륨 변화는 $3 \mathrm{D}$ 이미지 분석 소프트웨어에 의해 평가되었다. 결과: 샘플 $\mathrm{A}$ 의 경우 바르고 30 분 후 입술 주름이 감소하였다. 그리고 볼륨감의 효과가 동시에 나타났다. 두 결과 모두 통계적으로 유의미했다. 그러나 기준선에 비해 주름 완화 및 볼륨 증가 효과는 3 주 만에 통계적으로 차이가 없었다. 반면 샘플 $\mathrm{B}$ 는 주름 완화 효과와 볼륨 증가 효과가 모두 30 분대에 나타났고 3 주 후에도 지속됐다. 또한 주름 등급은 전문가들에 의해 측정되었다. 그리고, 비슷하게 샘플 B가 입술 주름의 강도를 효과적으로 감소시킨다는 것을 발견했다. 결론: 결론적으로 석류꽃 추출물이 함유된 샘플 $\mathrm{B}$ 는 장기적으로 주름 완화 효과와 입술 부피를 증가시키는 효과를 보였다. 이 연구에서는 석류꽃 추출물에 의한 기능성 화장품의 개발 가능성을 제시한다.

핵심어: 석류꽃, 립글로스, 주름, 플럼핑 효과, 볼륨감 효과

본 연구는 2019년 대한민국 교육부와 한국연구재단의 지원을 받아 수행된 연구임(NRF-2019S1A5B5A07088081).

\section{참고문헌}

곽미소. 주름개선 기능성화장품 소재개발 연구동향 분석. 미용예술경영연구, 11: 1-19, 2017.

김혜경, 권숙희, 김순자, 박은주, 서추연, 이숙녀, 전은경, 조정미. 피복인간공학 실험설계방법론. 교문사, 서울, $\mathrm{p} 46$, 1997.

서기석, 이진우, 최수영, 김상태. Asiaticoside의 입술 주름 개선 효과. 고신대학교 의과대학학술지, 22: 220-231, 2007. 안은주, 김정희. Hydrongenated Styrene/Isoprene Copolymer를 이용한 천연 립 틴트의 제조 및 효능평가. 한국미용학 회지, 25: 408-416, 2018.

(주아모레퍼시픽. 립-플럼핑 및 주름 개선 효과를 주는 입술용 화장료 조성물. 대한민국특허 등록번호 1014210490000 , 2008.02.29.

(주)엘지생활건강. 수용성 주름개선 성분을 함유하는 이중구조 립스틱 및 그제조방법. 대한민국특허 등록번호 1005823480000, 2005.01.08.

이정민, 유민정. 아로니아 잎 추출물을 이용한 화장품 소재 개발. 아시아뷰티화장품학술지, 16: 179-190, 2018.

정정희, 류희욱. 일본 떡을 이용한 립 메이크업 제품의 보습능 평가에 대한 유효성 평가. 아시아뷰티화장품학술지, 11 :

577-584, 2013. 


\section{中文摘要}

\section{含石榴籽花提取物的唇彩及其丰唇作用}

宋솔희, 閔惠照, 金玟周, 金柾希

圆光大学自然大学美容设计学科, 全罗北道益山市, 韩国

目的: 润唇膏是用于暂时增加唇部体积的美容剂。皮肤病学文献很少讨论嘴唇丰满的局部作用。进行这项研究 以评估唇部化妆品的丰盈效果。方法: 我们准备了三种不同的唇彩：对照品（基础唇彩），样品A（2\%的姜黄 根油）和样品 $\mathrm{B}(2 \%$ 的石榴花提取物）。为了评估其疗效, 招募了 30 名韩国女性受试者（年龄在30-49岁之 间），没有唇部疾病的临床病史。在涂上唇彩后的 $0 \mathrm{~min}, 30 \mathrm{~min}$ 和3周时准备好嘴唇的印记。扫描电子显微镜 用于扫描印模。印象中的体积变化通过3D图像分析软件进行评估。结果: 对于样品A, 在施用后 $30 \mathrm{~min}$, 嘴唇上 的皱纹强度降低, 并且同时看到了蓬松效果。两项结果均具有统计学意义。但是, 与基线相比, 三周后的皱纹 缓解和丰盈效果没有统计学上的显着差异。另一方面, 样品 $\mathrm{B}$ 在 30 分钟后既降低了皱纹强度, 又显示出丰满效 果, 并持续了3周。另外, 皱纹等级由专家测量。结论: 总而言之, 含有石榴籽花提取物的样品具有缓解皱纹和 增加嘴唇体积的长期效果。这些结果支持使用石榴属植物花提取物开发功能性化妆品的可能性。

关键词: 石榴花，唇蜜，皱纹，丰满效果，丰盈效果 